This said we must remind ourselves that the book is the result of his preparing himself, as his conscience dictated he must, "to introduce the theme of the social relations of science and technology" to the average second year university student of natural science. In this aim he has succeeded brilliantly. Such students with 'A' levels in physics and chemistry should be able fully to understand the scientific, technological and engineering content. Moreover, based either on my own recollections of myself 40-odd years ago or on conversations with present-day students I am convinced that the style, topics and sentiments displayed in the book should have a strong appeal to the sense and sensibilities of young adults. They should find it as fascinating as a good novel, replete with characters whose individual and collective attributes are mirrored in many of their seniors and who face issues of great contemporary relevance and importance. I hope that they will put it down with the feeling that their generation has to meet the challenge of how the scientist is to be the critical symbiont of the larger society of which he is a part, helping to shape its purposes rather than becoming either the parasite or the passive helot of a society to whose aims he is indifferent if not hostile.

\section{Unexpected treasures}

The Compacted States of Vitreous Silica. By William Primak (Studies in Radiation Effects in Solids, Vol. 4.) Pp. xv+184. (Gordon and Breach: New York, London and Paris, 1975.) $£ 10.70$.

Considering the terrestrial abundance of silica and the crucial position it holds in several fields of technology, our understanding of its structure and solid-state chemistry is deplorably vague. An excuse can be given-that the solid states of $\mathrm{SiO}_{2}$ are many and complex and have frustrated many conventional attacks - but the response of science has been lax. Pure scientists, instead of mounting more unconventional attacks, can be accused of generally turning away from the problems and letting the technologist flounder. A short list of technological uses of silica includes transmitting and reflecting optics, ceramics, piezoelectric devices, crucibles, passivating and insulating films; some unusual thin-film cantilever structures are now being used for displays and other purposes. In many of these applications, vitreous silica is used and yet, because conventional crystallography cannot work on such amorphous structures,
There is yet another reason why, were I still a professor, I would strongly recommend this book to my students and more particularly to their nonscientific contemporaries. It is simply that the book conveys in a lucid and lively manner the essence of the attitudes of scientists and by marked contrasts of style and matter jolts the reader into new thoughts. Thus it is serious in intent but impish in style, reverant and irreverent by turn, and popular-almost shallow treatment of some matters nevertheless often contain implicit or explicit insights of some depth. They serve to give the book a touch of human frailty seeming to put the author on the same level as the readers and thus encouraging them to think critically rather than be the passive receptors of the dispensed, predigested pabulum of scientific authority proffered to them in the textbooks. But scholars will sigh over inaccuracies and over-simplications or exaggerated phrases, and twice I narrowly escaped apoplexy. No reader will be indifferent and the young will be stimulated as the author wanted them to be. All that remains to be asked for is a paper back at half the price of the hard copy.

Sir Frederick Dainton is chairman of the University Grants Committee of the UK.

ignorance of this state of the material is the greatest.

Primak's book-length review article presents a highly individual view of the structure of this amorphous material, based on physical measurements which can certainly be classed as unconventional but were superbly adapted to the problem. Compaction is an effect which occurs only in non-crystalline solid networks (perhaps even only in oxide networks but Primak omits to tell us if any non-oxide glasses will compact); it is produced by pressure-cycling, high temperature, shock waves or radiation and can so alter the vitreous silica network that density is permanently reduced as much as $15 \%$ for pressure, and $3 \%$ for the others. Alkali silicate glasses will compact even more. This behaviour is so foreign to our concepts of immutable lattice constants that it is scientifically important; technological uses are, of course, also conceivable. Primak's own work, mainly on radiation-induced effects, is a classic of well-performed experimental study, augmented by careful but not hidebound interpretations. His hypothesis for the compaction was startling in that it went clean against the instinctive feeling of other workers that an increase in density implied an increase in order (fused silica is less dense than quartz).
He supplies ample evidence that silica can reduce its volume by the formation of a 'kink' in the large (say twelve-atom) rings of the silica network so that a 'void space' which was previously empty is newly occupied and order thereby decreased. But why should the kink be retained? The wider, new idea comes in the proposal that the silica network is in "a microscopic state of balanced stress" and that an excitation, producing one kink, causes the whole local structure to rearrange, perhaps in the form of a "network segment" which re-configures its quota of non-bridging oxygen atoms. Although Primak does not elaborate the model with any theoretical solidstate physics, it is still a very meaty and useful hypothesis. The book is a pursuit of its proof through every scrap of evidence available (there are over 350 references). Although the book was conceived nine years ago and largely finished six years ago, the central hypothesis and the suggestions for further investigations remain valid. Appendices embrace new research up to 1973 .

Only occasionally does the relaxed personal style lead to vagueness; for example, the author never tells us the best estimate for the $\mathrm{Si}-\mathrm{O}-\mathrm{Si}$ bond angles and lengths in the seven main phases of silica, and this sort of thing does detract from the introductory value. Later chapters are packed with intense and creative reasoning. Parochialism sometimes shows up herefor example in the lack of use which Primak has made of the electronicoptical disciplines of solid-state physics - for example, he does not explain the relevance of infrared spectra, or more than quote a few measurements. His only definite error in the electronic field is to say that "vitreous silica has no proper band structure", a common but unfortunate misconception, disproved by Di Stefano and others; the field of colour centres is dismissed as a "morass" and, although work on thin silica films is mentioned in passing, he has failed to note a valiant attempt made in 1969 by $\mathrm{H}$. L. Hughes to explain $\gamma$-ray-induced surface-state generation in such films, using a compaction model correlating his and Primak's data. One feels that great benefit would have been bestowed on the world if the author had wandered a bit further in these fields.

The book does give people interested in silica a chance to revel in a refreshing minor tributary of knowledge which may yet do great things for the mainstream. By his pleasant but creative style the author indicates some of the unexplored creeks which could yield unexpected treasures from the most abundant material in the earth's crust.

Andrew Holmes-Siedle 